Original Research Paper

\title{
Development of Porous Ti-6Al-4V Mix with Palm Stearin Binder by Metal Injection Molding Technique
}

\author{
Mohamad Ikhwan Jamaludin, Nur Atikah Abu Kasim, \\ Nor Hafiez Mohamad Nor and Muhammad Hussain Ismail \\ Centre for Advanced Materials Research (CAMAR), Faculty of Mechanical Engineering, \\ University Technology of MARA (UiTM), 40450 Shah Alam, Selangor, Malaysia
}

Article history

Received: 27-03-2015

Revised: 28-10-2015

Accepted: 29-10-2015

Corresponding Author: Mohamad Ikhwan Jamaludin Centre for Advanced Materials Research (CAMAR), Faculty of Mechanical Engineering, University Technology of MARA (UiTM), 40450 Shah

Alam, Selangor, Malaysia Tel: +60196106905

Email: ikhwanjamal@gmail.com

\begin{abstract}
Good potential of biocompatibility and excellent mechanical properties, porous $\mathrm{Ti}-6 \mathrm{Al}-4 \mathrm{~V}$ has become a great interest for biomedical applications. In this study, porous Ti-6Al-4V was fabricated by Metal Injection Molding (MIM) using Palm Stearin (PS) and Polyethylene (PE) binder together with sodium chloride $(\mathrm{NaCl})$ as a space holder. Rheological characterization was performed to evaluate the flowability of the feedstocks for injection molding and the feedstocks exhibited a pseudoplastic behavior which is suitable for injection. The as-sintered parts were fabricated as the mixing, injection molding, debinding and sintering were conducted successfully. The mechanical properties of the as-sintered parts were investigated via tensile test and the results obtained were closed with the established range. Shrinkage, density and X-Ray Diffractometry (XRD) of the as-sintered parts were compared with the theoretical values which were found closed to the acceptable ranges. The microstructure of the surface and cross-section were observed under Scanning Electron Micrograph (SEM) and optical microscope to analyze the specimens before and after sintering. Generally, palm stearin binder system added with space holder to fabricate porous Ti-6Al-4V by MIM is feasible and has shown a good potential for biomedical applications.
\end{abstract}

Keywords: Metal Injection Molding (MIM), Porous, Ti-6Al-4V, Palm Stearin, Space Holder

\section{Introduction}

Recently, there is a substantial demand in a market of Metal Injection Molding (MIM) as a new technique to manufacture supplies for biomedical applications (Froes and Froes, 2006). MIM has a capability to produce intricate shapes product, ranging from tiny to huge at low cost in high volumes. In addition, several methods have been introduced in MIM to fabricate a porous structure for biomedical applications such as space holder method and partial sintering method (Torres et al., 2012; Ismail et al., 2012). There are four consecutive basic steps in MIM: Mixing, injection molding, debinding and sintering. In the mixing process, selected metal powder at certain size $(\mu \mathrm{m})$ and binders are mixed together at appropriate volumetric ratio to synthesize a homogenous feedstock. Binder system plays a main role to provide lubrication during injection molding flow by uniformly coating the metal powder and filling all gaps between the powder particles. The homogenous feedstock then undergoes injection molding to shape the feedstock known as a green part. Debinding process takes place after the injection molding to eliminate the binders from green part and the debound specimen is called as a brown part. Finally, the brown part is sintered to remove the residual binders and bond the metal powder particles together to produce an assintered part (German and Bose, 1997).

Binder system selection has an important influence on the success of MIM production especially involves with Ti-based product that easily contaminated by the binders (Scott Weil et al., 2006). Novel binder system offers free of impurities, good flow characteristic, rapid debinding procedure, cost-effective and environmental friendly (German, 2005). Lately, improvements of binder system have become great interests among research communities to develop a novel binder system. Palm Stearin (PS) binder system which introduced by Iriany et al. (2001) has the advantages to overcome contaminants drawback and long debinding procedures. 
Besides that, PS is biodegradable, cheap and readily availability in Malaysia which is suitable to be substituted with a complex multi-components conventional binder system.

Ti-6Al-4V has been highlighted for biomedical applications due to its good biocompatibility and excellent mechanical properties (Leyens and Manfred, 2006). To date, a lot of studies have been conducted focusing on developing highly porous $\mathrm{Ti}-6 \mathrm{Al}-4 \mathrm{~V}$ for biomedical applications. In this study, PS and PE binder with sodium chloride $(\mathrm{NaCl})$ as the space holder was mixed with Ti-6Al-4V metal powder particles to fabricate porous Ti-6Al-4V by MIM technique. The physical, mechanical and microstructural properties of the as-sintered porous Ti-6Al-4V have been evaluated for further analysis of potential biomedical applications.

\section{Materials and Methods}

\section{Characterization of Materials}

Ti-6Al-4V metal powder used in this research was gas atomized powder provided from TLS Technik GmBH. The characteristics and the chemical composition of Ti-6Al-4V metal powder are shown in Table 1 and 2 respectively.

In this investigation, irregular shape of $\mathrm{NaCl}$ was used as a space holder with a particle size ranging between $150 \mu \mathrm{m}$ to $200 \mu \mathrm{m}$. The volume fraction of metal powder to space holder was set to 50:50 to represent powder constituent in order to produce $50 \%$ porosity. The binder system used in this investigation comprises of Palm Stearin (PS) as a primer binder and Polyethylene (PE) as a backbone binder with a binder volume fraction of PS: PE was set to 60:40.

\section{Feedstock Preparation}

In this process, Brabender Plastograph EC mixer was used for mixing. Three different powder loadings of feedstock were prepared; 63, 64 and 65 vol.\%. The temperature of mixer was set to $150^{\circ} \mathrm{C}$ and the speed of the blade was set to $50 \mathrm{rpm}$. Then, PE and PS were fed into the mixer gradually to lubricate the mixing process followed by $\mathrm{Ti}-6 \mathrm{Al}-4 \mathrm{~V}$ powder and $\mathrm{NaCl}$ after the binders were melted. After the insertion of all mixture components was done, the mixture blade was continued rotating for one hour to attain a homogenous paste.

Table 1. The physical properties of Ti-6Al-4V metal powder

\begin{tabular}{ll}
\hline Shape of particle & Sphere \\
\hline Size of particle & $<22 \mu \mathrm{m}$ \\
Pcynometer density & $4.3827 \mathrm{~g} / \mathrm{cm} 3$ \\
Melting point & $1650^{\circ} \mathrm{C}$ \\
\hline
\end{tabular}

Table 2. Chemical composition of the supplied Ti-6Al-4V metal powder

\begin{tabular}{llllllll}
\hline $\mathrm{Al}$ & $\mathrm{V}$ & $\mathrm{C}$ & $\mathrm{Fe}$ & $\mathrm{O}$ & $\mathrm{N}$ & $\mathrm{H}$ & $\mathrm{Ti}(\mathrm{wt} \%)$ \\
\hline 5.99 & 4.08 & 0.005 & 0.043 & 0.185 & 0.004 & 0.002 & $\mathrm{Bal}$ \\
\hline
\end{tabular}

\section{Rheology and Injection Molding}

The assessment of flowability through rheological characterization was performed using Malvern Ros and RH2000 capillary rheometer. Relationship of nonnewtonian fluids between viscosity and shear rate could be defined as follows:

$\eta=K \gamma^{n-1}$

Where:

$\eta=$ Feedstock viscosity

$K=$ A constant

$\gamma=$ A shear rate

$n$ = A flow behavior index

The effect of shear rate on feedstock viscosity can be determined by Equation 1. Usually, for non-newtonian fluid of pseudoplastic $(n<1)$ substances exhibit a decrease of viscosity as the shear rate increase.

For injection molding, the process was done by using low-cost custom-made vertical injection molding and tensile mold which both developed by Azuddin et al. (2014). The parameters of injection molding were selected based on the optimized parameters studied by Mohamad Nor et al. (2011a) to reduce trial and error procedures. Hence, the barrel of the injection molding machine temperature was set to $150^{\circ} \mathrm{C}$ with the injection pressure of $0.8 \mathrm{MPa}$. The injection plunger was held for $10 \mathrm{sec}$ before the ejection of the samples from the mold.

\section{Debinding}

There were 3 subsequent stages of debinding in this study: Solvent debinding, water leaching and thermal debinding. The debinding parameters were designated based on the previous work by Jamaludin et al. (2014) on parameter optimization of debinding Ti-6Al-4V. The debinding process started with solvent debinding where the green parts were dissolved in heptane solution for 6 $\mathrm{h}$ at $60^{\circ} \mathrm{C}$ to remove PS. After that, $\mathrm{NaCl}$ was leached out by soaking the specimens in distilled water for $12 \mathrm{~h}$ at $60^{\circ} \mathrm{C}$. Lastly, the specimens underwent thermal debinding to remove PE. In MIM, thermal debinding is normally incorporated with sintering process in the same furnace. Thermal debinding procedure will be discussed in details in the sintering stage.

\section{Sintering}

Sintering is the final step in MIM where the metal powder particles were bond together and densified. The specimens were place in a Molybdenum (Mo) box to prevent the reaction of residual binder to the heating element of the furnace and secure the heating process. The furnace used was KOREA VAC-TEC high temperature control atmosphere furnace. 


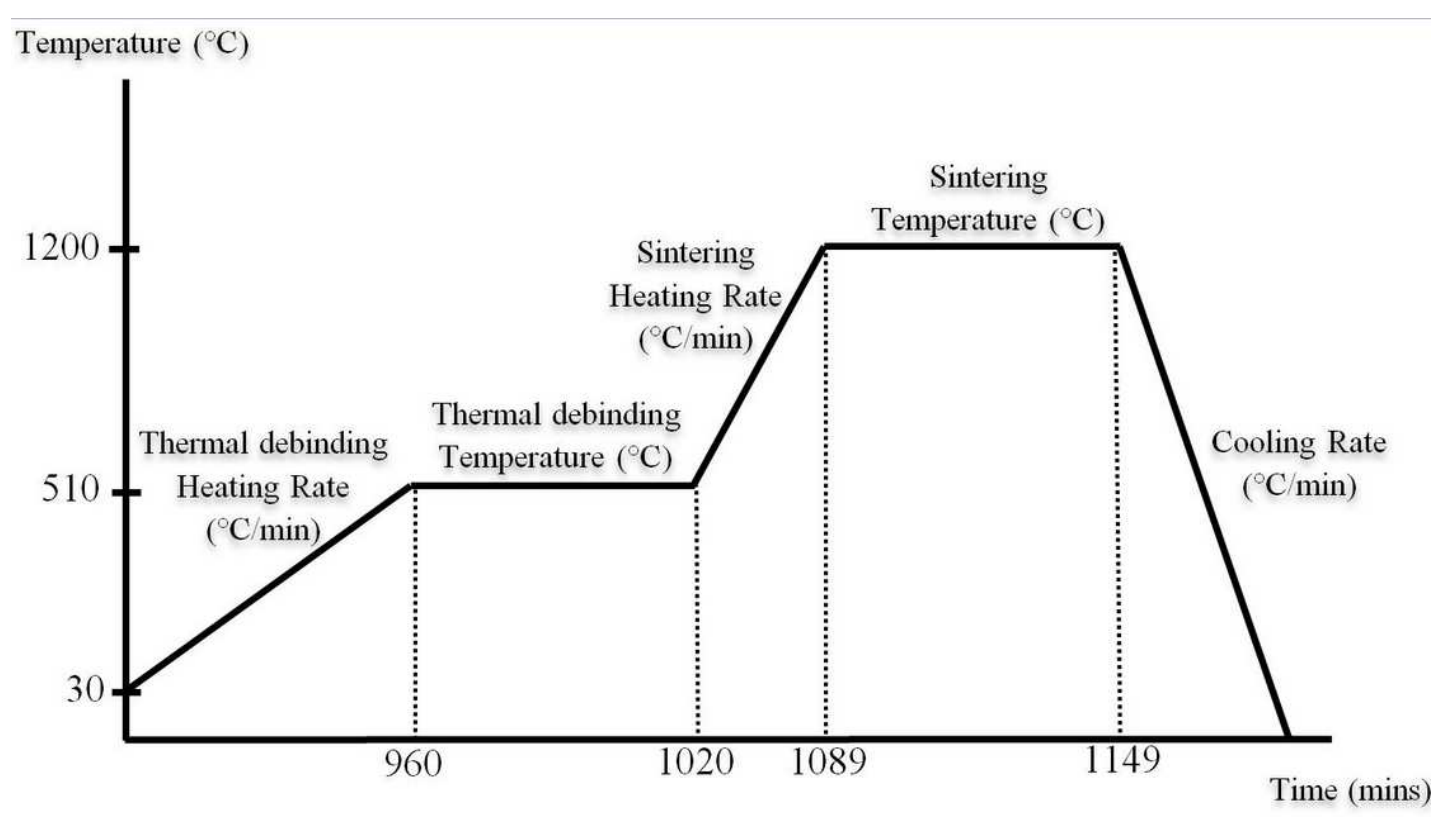

Fig. 1. Thermal debinding and sintering cycle applied for tensile bar test specimens

Two stages of heating were applied which the first stage was for thermal debinding and the second stage was for sintering. A few trial and error procedures were performed based on the parameters from previous work by Mohamad Nor et al. (2013) before the finalized parameters were set to be optimum parameters which given in Fig. 1. Thermal debinding was started by increasing the temperature gradually heating rate of $0.5^{\circ} \mathrm{C} / \mathrm{min}$ and kept for $1 \mathrm{~h}$ after achieved to $510^{\circ} \mathrm{C}$. Then, the temperature was increased to $1200^{\circ} \mathrm{C}$ with the rate of $10^{\circ} \mathrm{C} / \mathrm{min}$ and soaked at same temperature for $1 \mathrm{~h}$ before it was cooling down as the experiment approaches to the end.

\section{Characterization of the As-Sintered Parts}

Theoretically, the volume will decrease after sintering process as the process eliminates the voids that contained trapped air and residual binder in the brown part. For physical properties analysis, the dimensional changes and the density were measured using Vernier caliper and densitometer that applies Archimedes principle respectively after sintering process. Porosity of the as-sintered parts was calculated based on direct method calculation using equation as follows (Liu and Chen, 2014):

$\theta=\left(1-\frac{M}{V^{*} \rho_{s}}\right) \times 100 \%$

Where:

$V=$ The total volume of the specimen

$M=$ The mass of the sample $\rho_{s}=$ The solid density of the materials

Besides that, porosity of the as-sintered parts was also calculated by image analyzer to uphold the results from direct method of porous calculation.

Regarding mechanical properties, Shimadzu high precision universal testing machine AG-X was used for tensile strength test of the as-sintered sample. For micro structural analysis, the samples were cut, grinded and polished to attain a flat surface. Ultima IV Rigaku X-Ray Diffractometer was used for XRD analysis to scan at speed of $2 \% \mathrm{~min}$ in the range of $30^{\circ}-80^{\circ}$ in order to discover $\mathrm{Ti}-6 \mathrm{Al}-4 \mathrm{~V}$ phases and any interstitial element that presence on the aspolished sample. Then, optical microscope and Scanning Electron Microscope (SEM) was employed to inspect the microstructure of grain growth among inter-particles and porous analysis.

\section{Results and Discussion}

\section{Rheological Characterization and Injection Molding}

Rheological assessment of feedstock with three different powder loadings at 130,150 and $170^{\circ} \mathrm{C}$ were evaluated to assure the flow ability of the feedstock before injection molding. The results were given in Fig. 2 in terms of $\log$ shear viscosity $(\eta)$ versus $\log$ shear rate $(\gamma)$ based on Equation 1. Razali et al. (2014) reported the melting point of the backbone binder; PE is about $100^{\circ} \mathrm{C}$. Hence, the temperature of rheological test was tested in the range of $130^{\circ} \mathrm{C}$ to $170^{\circ} \mathrm{C}$ $\left(>100^{\circ} \mathrm{C}\right)$ based on the mixing process temperature. 


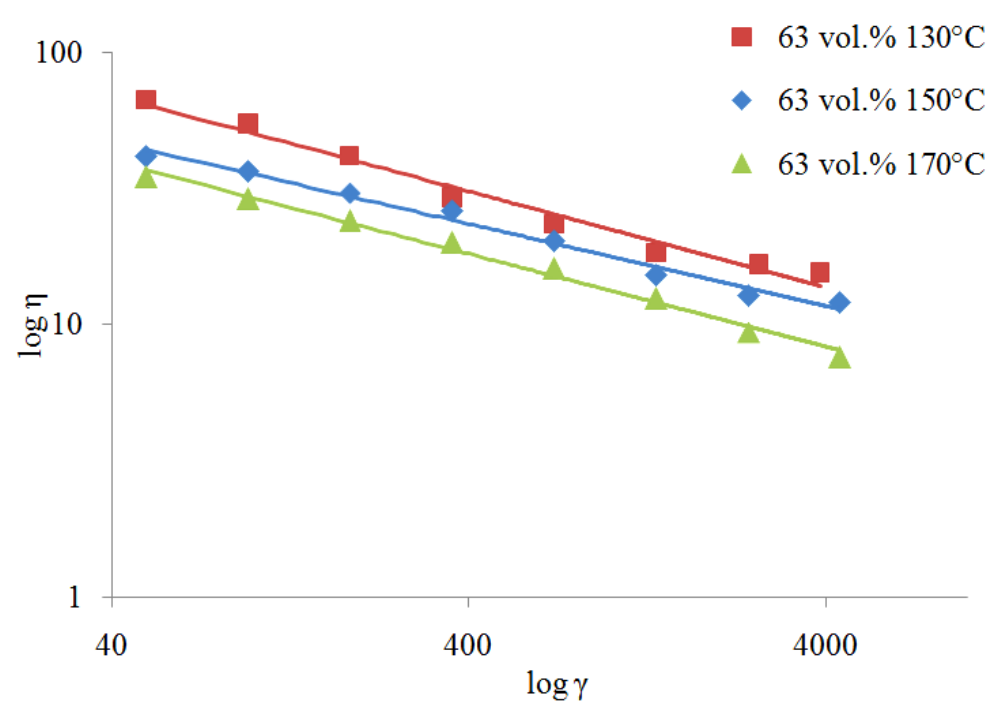

(a)

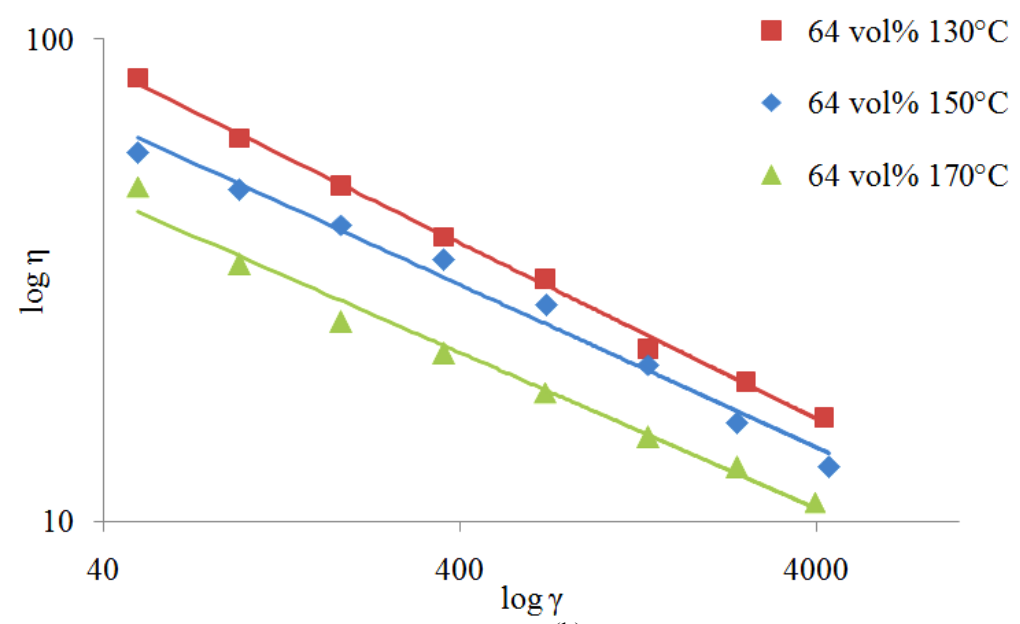

(b)

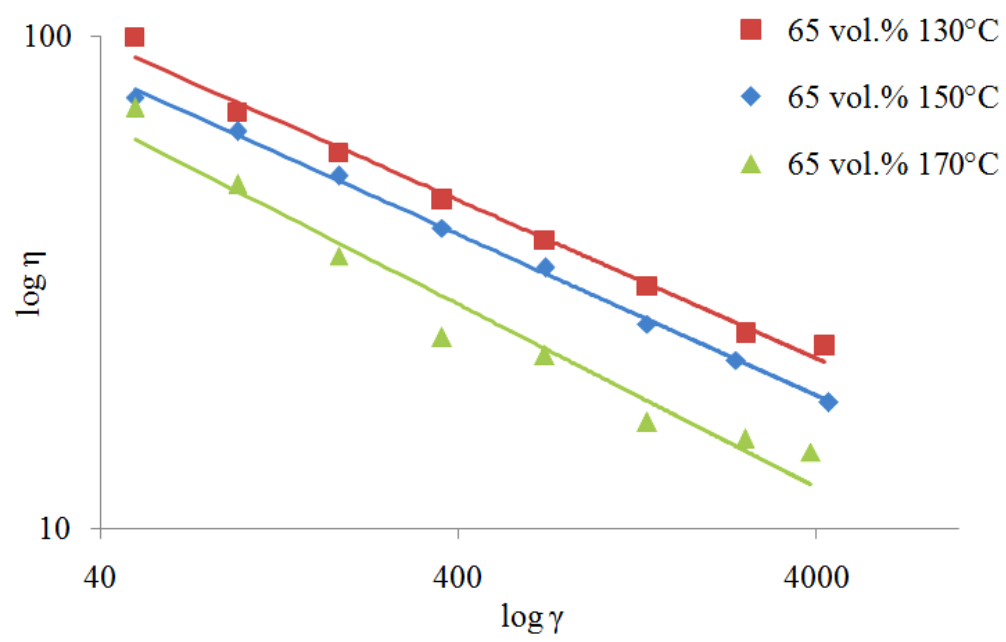

(c)

Fig. 2. Relationship between shear viscosity and shear rate of (a) 63 vol.\% (b) 64 vol.\% and (c) 65 vol.\% powder loading feedstock at different temperature 


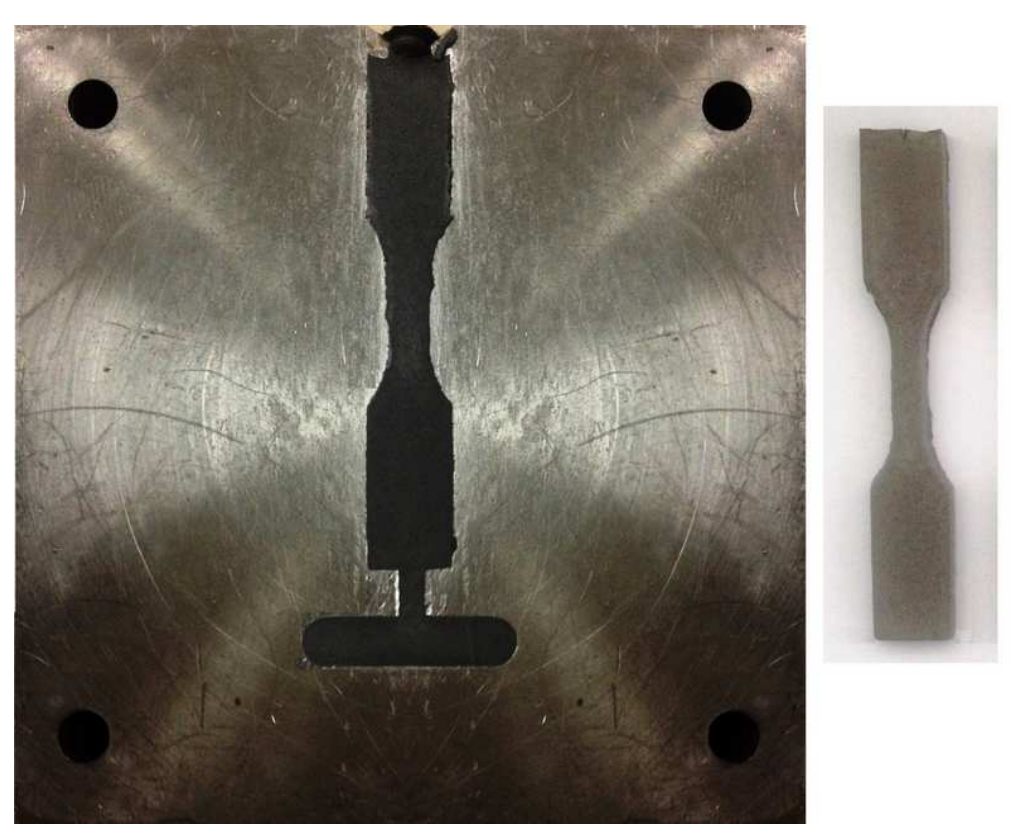

Fig. 3. Complete mold filling and the green part of porous Ti-6Al-4V feedstock

Table 3. Flow behavior index of feedstock at different temperature

\begin{tabular}{llll}
\hline Powder loading & 63 vol.\% & 64 vol.\% & 65 vol.\% \\
\hline $130^{\circ} \mathrm{C}$ & 0.646 & 0.635 & 0.673 \\
$150^{\circ} \mathrm{C}$ & 0.685 & 0.700 & 0.728 \\
$170^{\circ} \mathrm{C}$ & 0.710 & 0.728 & 0.741 \\
\hline
\end{tabular}

It is clearly shows the feedstock of all three powder loadings evaluated at 130,150 and $170^{\circ} \mathrm{C}$ have shown a pseudoplastic behavior, which increased of shear rate and temperature has decreased the viscosity. This result signified that the binder system used works well with the feedstock containing space holder material to impart good flowability for MIM. This result is also agreed with the previous work done by Mohamad Nor et al. (2011b) for the Ti-6Al-4V feedstock without the space holder.

Flow behavior index of feedstock $(n)$ tabulated in Table 3 is calculated from the slope of the graph based on the Equation 1. As the temperature increased, the flow behavior index was also increased. According to Omar et al. (2011), n-value describe how sensitive the feedstock viscosity against shear rate which the lower the $n$-value, the more sensitive feedstock against shear rate. Thus, feedstock with lower $n$-value is more recommended for injection molding because high shear sensitivity is essential to produce delicate and intricate parts (German and Bose, 1997). However, among the three temperatures, the extrudate at $170^{\circ} \mathrm{C}$ has the lowest shear viscosity and higher $n$-value compared to the extrudate at 130 and $150^{\circ} \mathrm{C}$. Too low viscosity can cause to the difficulties during injection molding such as powder-binder segregation due to shear thickening (Fayyaz et al., 2014).

\section{Injection Molding}

Figure 3 shows complete mold filling and ejected specimen of injection molded part from the mold. The injection process went smoothly and there were no defects were observed such as short shot, crack and sink mark. The optimum temperature and pressure set for injection molding was 150 and $450^{\circ} \mathrm{C}$ bar respectively (Mohamad Nor et al., 2010).

\section{Debinding}

PS and $\mathrm{NaCl}$ was completely removed through solvent debinding and water leaching based on the weight scaled analysis to calculate the percentage of removed PS and $\mathrm{NaCl}$. The results in Fig. 4 showed the extraction rate of $\mathrm{PS}$ and $\mathrm{NaCl}$ removal at optimum temperature, $60^{\circ} \mathrm{C}$. Higher temperature more than $60^{\circ} \mathrm{C}$ was not recommended to avoid cracks or swelling during solvent debinding (Jamaludin et al., 2014).

There was no defect on all specimens was found after the debinding process. As shown in Fig. 4, feedstock with lower powder loading has higher removal rate than higher powder loading due to higher amount of binder contain in the specimens. Besides that, the removal rate of $\mathrm{PS}$ and $\mathrm{NaCl}$ was rapidly increased until achieved plateau stage at certain period. Based on the study done by Sotomayor et al. (2011), solvent debinding typically consist of two stages; dissolution and diffusion. Higher rate of extraction during initial stage was because the solvent has direct contact with the solute (PS and $\mathrm{NaCl}$ ) so the distance is shorter. As the time increase, the rate of extraction become slower as the pore channels stretch out to the inner region of green specimen that lengthen the removal path (Chen et al., 2013). 


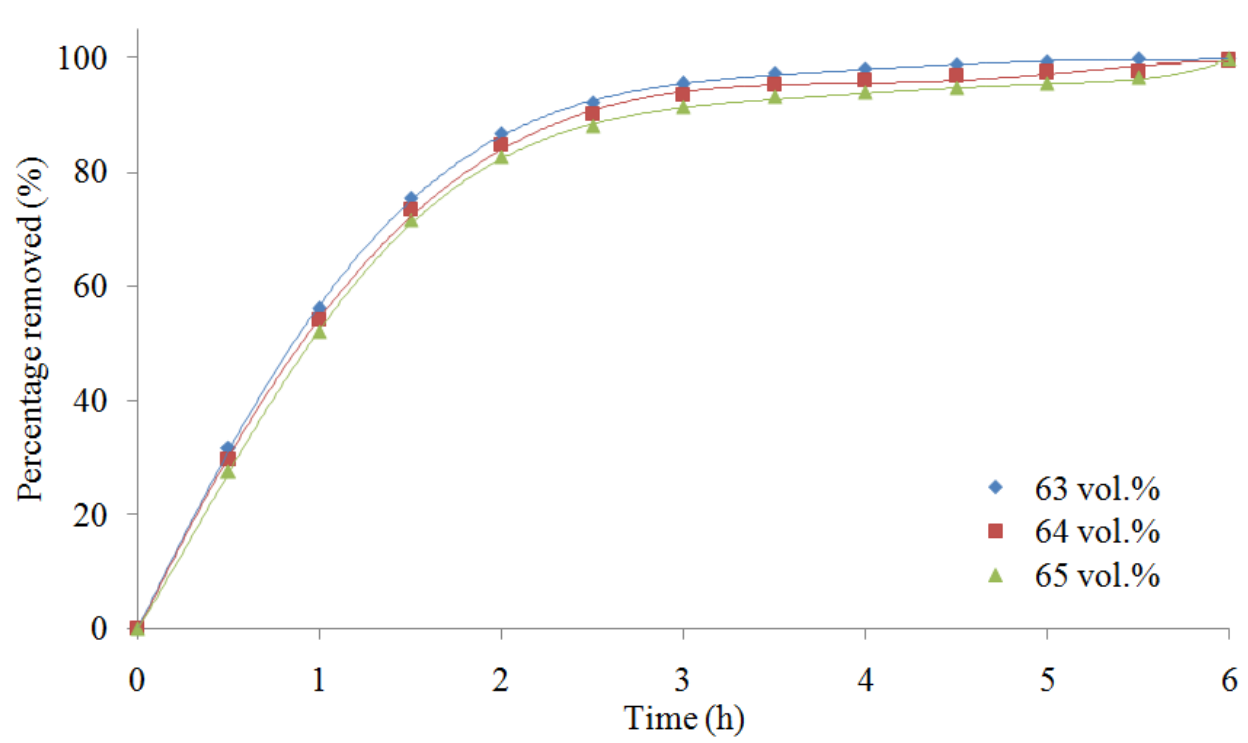

(a)

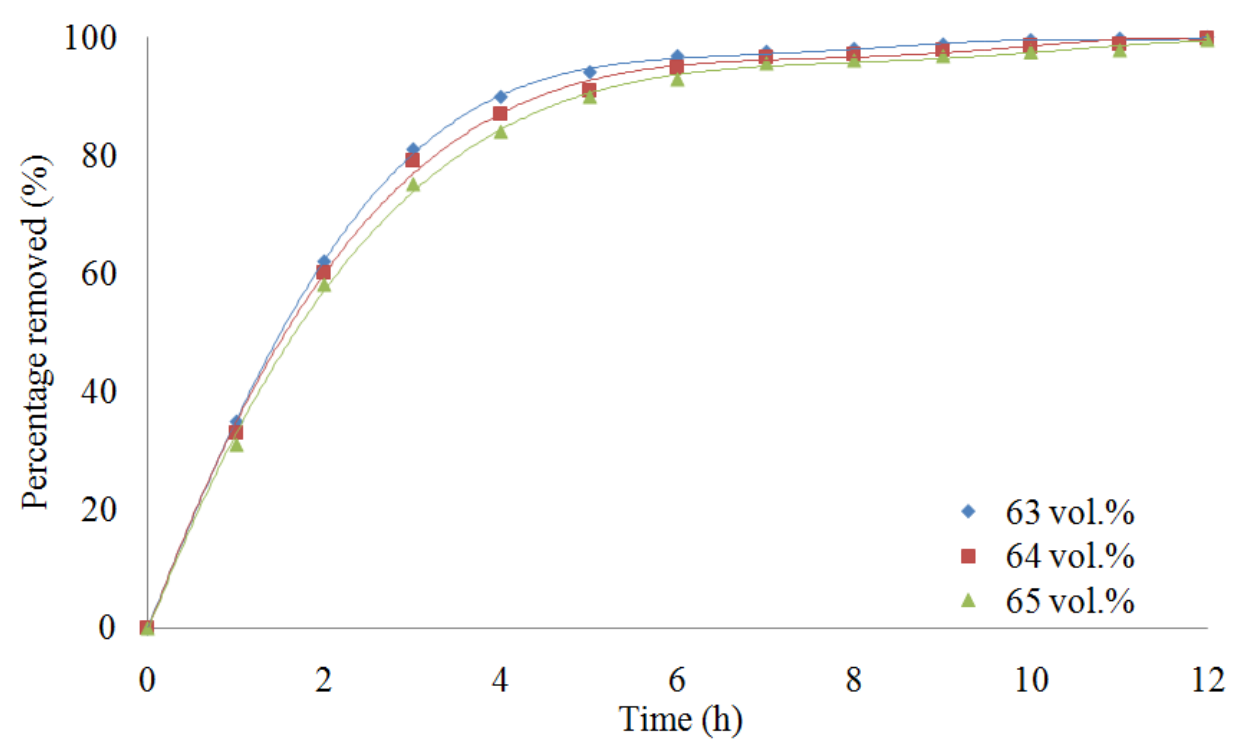

(b)

Fig. 4. Percentage removal of (a) PS and (b) $\mathrm{NaCl}$ over $6 \mathrm{~h}$ and $12 \mathrm{~h}$ respectively

The removal of PS and $\mathrm{NaCl}$ has produced network of pores as shown in Fig. 5 which has proved that PS and $\mathrm{NaCl}$ was thoroughly removed after solvent debinding and water leaching process.

\section{Thermal Debinding and Sintering}

All the specimens were successfully sintered without blisters, cracking or any form of deformation was found. Figure 6 shows the dimensional changes between green part, brown part and the as-sintered part. The shrinkage implied to the densification of the metal powder particles by elimination of pores left by the removed binders. Whereas, pores created by space holder can be observed on the as-sintered specimens through bare eyes.

\section{Characterization of the As-Sintered Samples}

In term of physical properties, the dimensional change indicates $24.53,23.5$ and $22.5 \%$ shrinkage for 63,64 and $65 \mathrm{vol} . \%$ powder loading respectively. The density of the as-sintered specimens of 63,64 and 65 vol.\% were $3.2377 \pm 0.025$ and $3.2856 \pm 0.014 \mathrm{~g} / \mathrm{cm}^{3}$ respectively. The difference between the as-sintered parts density and pycnometer density were 26.50, 25.94 and $25.03 \%$ respectively. Regarding porosity, it was found that from the calculation and porous image analyzer data, the porosity of the 63,64 and 65 vol.\% powder loading feedstock were $43.18,37.02$ and $35.15 \%$. 


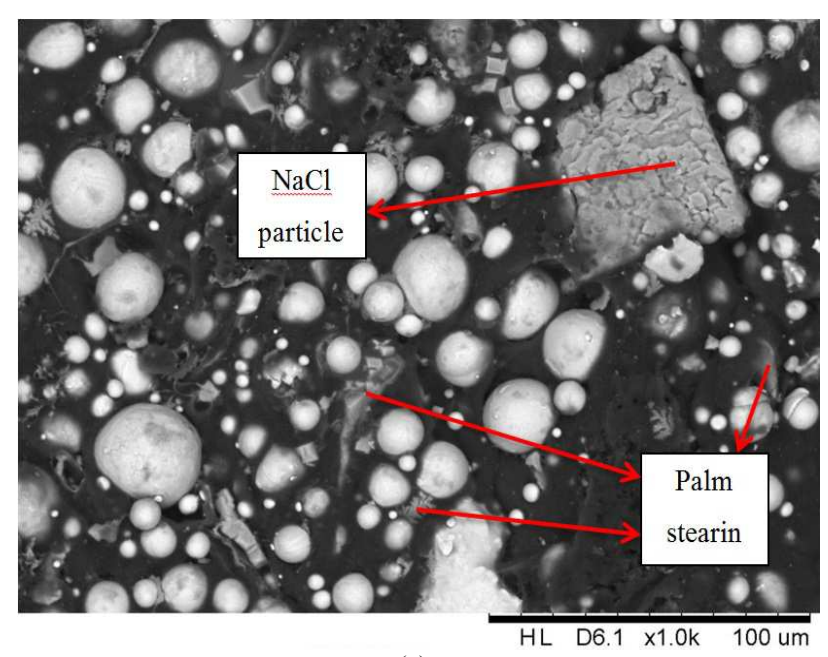

(a)

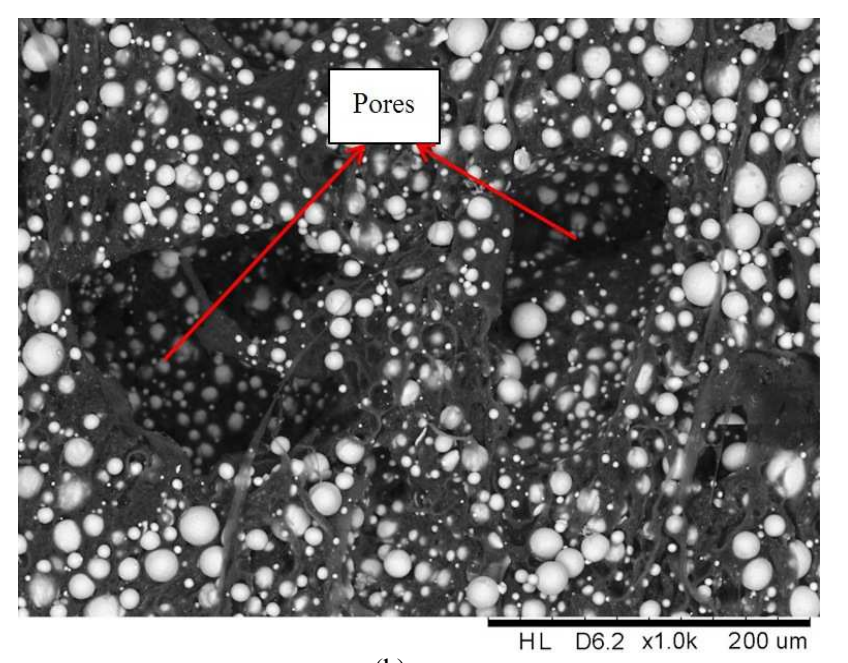

(b)

Fig. 5. SEM image of cross section of specimens: (a) before and (b) after solvent extraction and water leaching process

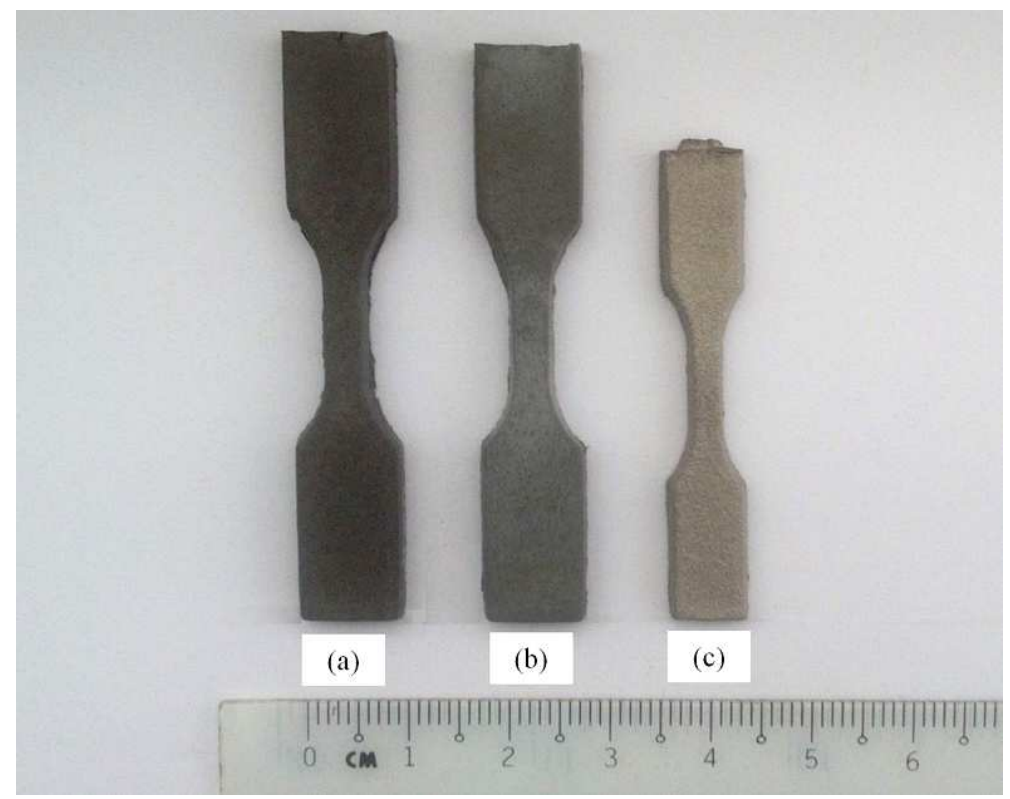

Fig. 6. Shrinkage effect before and after sintering (a) green part (b) PS and $\mathrm{NaCl}$ debound part (c) as-sintered part

Table 4. Mechanical properties of the as-sintered specimens

\begin{tabular}{lll}
\hline Materials & $\begin{array}{l}\text { Ultimate tensile } \\
\text { strength (MPa) }\end{array}$ & $\begin{array}{l}\text { Elastic } \\
\text { modulus (GPa) }\end{array}$ \\
\hline Sample 63 vol.\% & $430.81 \pm 15.4$ & $8.73 \pm 2.30$ \\
Sample 64 vol.\% & $476.35 \pm 9.8$ & $9.02 \pm 1.80$ \\
Sample 65 vol.\% & $478.30 \pm 12.6$ & $9.35 \pm 2.62$ \\
\hline
\end{tabular}

In comparison with the findings reported by Mohamad Nor (2013), the shrinkage of the as-sintered of dense Ti-6Al-4V was only 12 to $15 \%$. It was almost $50 \%$ less than the shrinkage of porous Ti-6Al-4V which is agreed to the 50:50 of powder to space holder volume percentage composition. As stated by Subuki (2010), there is less shrinkage, density and porosity as the green density increases which is agreed with the findings on this study. However, the porosity obtained from the specimens was below than the expected value $(50 \%$ porosity) caused by annihilation of the pores due to the effect of grain growth densification during the sintering process (German, 2005).

The assessment of mechanical properties was evaluated by tensile strength test and the results are given in Table 4.

From Table 4, it was observed that, high green density (65 vol.\%) sample has higher Ultimate Tensile Strength (UTS) than lower green density specimen. The elastic modulus of the samples also shows a similar trend with UTS results. The average strength from three powder 
loadings was $461.82 \pm 7.2 \mathrm{MPa}$ which this value is almost $50 \%$ lower than the strength of dense Ti- $6 \mathrm{Al}-4 \mathrm{~V}$ reported by Mohamad Nor (2013) which is $934.33 \mathrm{MPa}$.

The elastic modulus of the samples also shows the same trend with UTS results. It was predicted before the test that high green density samples has the ability to bear higher load compared to low green density. The elastic modulus of porous $\mathrm{Ti}-6 \mathrm{Al}-4 \mathrm{~V}$ was in the range of $8.73 \pm 2.30$ to $9.35 \pm 2.62 \mathrm{GPa}$ which is lower than the elastic modulus of dense Ti-6Al-4V reported by Mohamad Nor (2013). However, low value of elastic modulus is good for preventing stress shielding to match the mechanical properties of the human bone (Li et al., 2014).

As regard with microstructural analysis, Fig. 7 depicts the presence of lamellae of $\alpha$ on the surface of the as-polished sample. The presence of lamellae of $\alpha$ demonstrates that the transformation $\alpha(\beta \rightarrow \alpha)$ phase has separated the globular $\alpha$ and appears in terms of typical $(\alpha+\beta)$ phase of Ti-6Al-4V (Obasi et al., 2010). Thus, the presence of typical $(\alpha+\beta)$ phase as displayed in the Fig. 7 has confirmed the morphology of Ti-6Al$4 \mathrm{~V}$ phase (Murr et al., 2009).

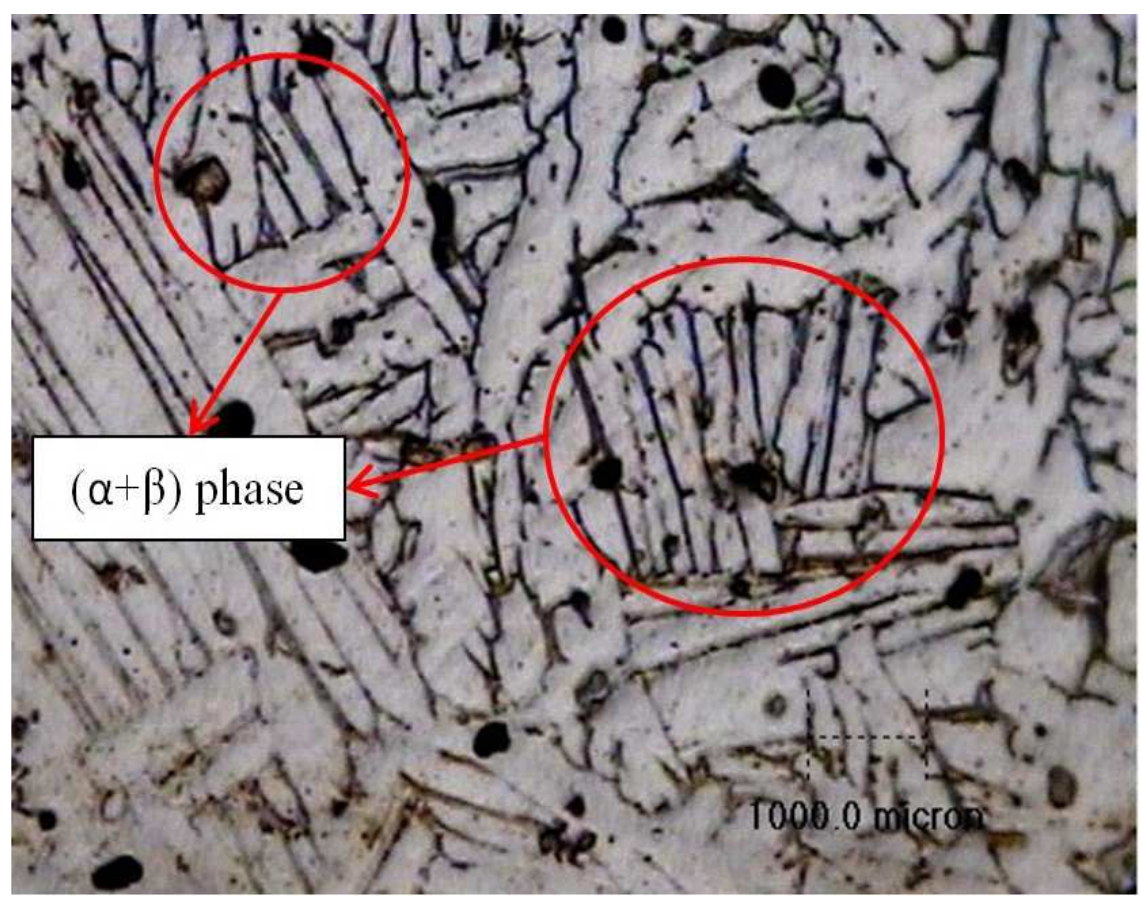

Fig. 7. The as-polished sample observed under optical microscope

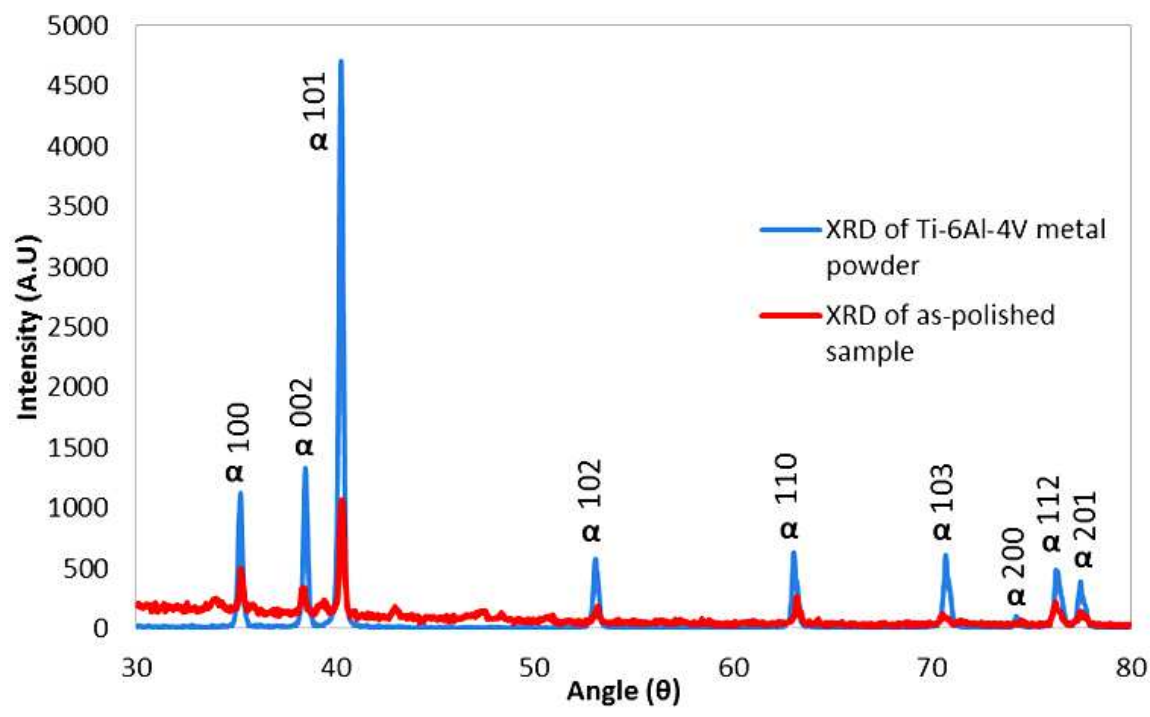

Fig. 8. XRD pattern of porous Ti-6Al-4V as-polished sample 
XRD was employed to determine the phase of the aspolished specimen which the results shown in Fig. 8. The primary $\alpha$ peak of as-polished porous Ti-6Al-4V sample was shorter and narrower compared to the primary $\alpha$ peak of Ti-6Al-4V metal powder. This is because the difference of sample morphology in solid form has lowered the intensity of diffraction patterns compared to the sample morphology in form of powder. The surface of Ti-6Al-4V metal powder sample was uniform and smooth. In contrast, the surface of the aspolished sample was rough which cause some of the Xrays were diffracted away from the sensor. Thus, the peaks of primary $\alpha$ of the as-sintered sample appeared shorter and narrower than the peaks of Ti-6Al-4V metal powder. This was confirmed the phases on the aspolished sample represent the phases of standard Ti-6Al$4 \mathrm{~V}$ without any other interstitial element found on the as-polished sample (Mohamad Nor, 2013).

\section{Conclusion}

In the present work, porous Ti-6Al-4V mix with PS binder system with powder loading of 63, 64 and 65 vol.\% was successfully fabricated by MIM technique. All the major steps of MIM from mixing, injection molding, debinding and sintering were accomplished successfully. The finding of mechanical properties closed to the range of bone has shown a great potential of porous Ti-6Al-4V for biomedical applications. Improvements on powder loading and flowability can be considered for future work to match the mechanical as well as physical properties of the bone.

\section{Acknowledgement}

This work was conducted under grant number: 600-RMI/FRGS 5/3 (23/2012) and 600- RMI/FRGS 5/3 (38/2012) in Universiti Teknologi MARA (UiTM Shah Alam). The author wishes to thank to Dr. Abu Bakar Sulong from Universiti Kebangsaan Malaysia (UKM), Dr. Azuddin Mamat from University Malaya (UM) and Dr. Rosdi Ibrahim from AMREC, SIRIM for the equipment.

\section{Author's Contributions}

Mohamad Ikhwan Jamaludin: Performed the experiments, data analysis and contributed to the writing of the manuscript.

Nur Atikah Abu Kassim: Assisted the preparation of the sample and experiments.

Nor Hafiez Mohamad Nor: Developed the concept and assisted in interpreting data analysis of the experiment.

Muhammad Hussain Ismail: Assisted in interpreting data analysis of the experiment.

\section{Ethics}

This article is original and contains unpublished material. The corresponding author confirms that all of the other authors have read and approved the manuscript and no ethical issues involved.

\section{References}

Azuddin, M., I.A. Choudhury and Z. Taha, 2014. Development and performance evaluation of a lowcost custom-made vertical injection molding machine. J. Brazilian Society Mechan. Sci. Eng., 37: 79-86. DOI: 10.1007/s40430-014-0145-z

Chen, G., P. Cao, G. Wen and N. Edmonds, 2013. Debinding behaviour of a water soluble PEG/PMMA binder for Ti metal injection moulding. Mater. Chem. Phys., 139: 557-565. DOI: 10.1016/j.matchemphys.2013.01.057

Fayyaz, A., N. Muhamad, A.B. Sulong, H.S. Yunn and S.Y.M. Amin et al., 2014. Rheological properties of cemented tungsten carbide feedstock for micro powder injection. Mater. Sci. Forum, 773-774: 827-832. DOI: 10.4028/www.scientific.net/MSF.773-774.827

Froes, F. and S. Froes, 2006. Getting better: Big boost for titanium MIM prospects. Metal Powder Report, 61: 26-29. DOI: 10.1016/S0026-0657(06)70762-7

German, R.M., 2005. Powder Metallurgy and Particulate Materals Processing: The Processes, Materials, Products, Properties and Applications. 1st Edn., Metal Powder Industries Federation, Princeton, ISBN-10: 0976205718, pp: 528.

German, R.M. and A. Bose, 1997. Injection Molding of Metals and Ceramics. 1st Edn., Metal Powder Industries Federation, Princeton, ISBN-10: 187895461X, pp: 413.

Iriany, A.K.A., N. Muhamad and J. Sahari, 2001. Stability of metal injection molding feedstock containing palm oil. J. Instit. Mater. Malaysia, 3: 71-83.

Ismail, M.H., R. Goodall, H.A. Davies and I. Todd, 2012. Porous NiTi alloy by metal injection moulding/sintering of elemental powders: Effect of sintering temperature. Mater. Lett., 70: 142-145. DOI: 10.1016/j.matlet.2011.12.008

Jamaludin, M.I., N.H. Mohamad Nor, N.A. Abu Kasim, J.B. Saedon and N. Muhamad, 2014. Parameter optimization of debinding injection moulded Ti$6 \mathrm{Al}-4 \mathrm{~V}$ mix with palm stearin and polyethylene. Applied Mechan. Mater., 660: 234-238. DOI: $10.4028 /$ www.scientific.net/AMM.660.234

Leyens, C. and P. Manfred, 2006. Titanium and Titanium Alloys: Fundamentals and Applications. 1st Edn., John Wiley and Sons, Weinheim, ISBN-10: 3527605207, pp: 532. 
Li, Y., C. Yang, H. Zhao, S. Qu and X. Li et al., 2014. New Developments of Ti-Based Alloys for Biomedical Applications. Materials, 7: 1709-1800. DOI: $10.3390 / \mathrm{ma} 7031709$

Liu, P. and G.F. Chen, 2014. Porous Materials: Processing and Applications. 1st Edn., Elsevier Science, Burlington, ISBN-10: 0124078370, pp: 576.

Mohamad Nor, N.H., 2013. Optimisation process of Ti$6 \mathrm{Al}-4 \mathrm{~V}$ powder injection molding using palm stearin based binder. Universiti Kebangsaan Malaysia.

Mohamad Nor, N.H., N. Muhamad, S. Ahmad, M.H.I. Ibrahim and M.R. Harun et al., 2010. Parameter optimization of injection molding Ti-6Al-4V powder and palm stearin binder system for highest green density using taguchi method. Key Eng. Mater., 443: 69-74.

DOI: $10.4028 /$ www.scientific.net/KEM.443.69

Mohamad Nor, N.H., N. Muhamad, M.H.I. Ibrahim, M. Ruzi and K.R. Jamaludin, 2011a. Optimization of injection molding parameter of ti-6al-4v powder mix with palm stearin and polyethylene for the highest green strength by using taguchi method. Int. J. Mechan. Mater. Eng., 6: 126-132.

Mohamad Nor, N.H., N. Muhamad, K.R. Jamaludin, S. Ahmad and M.H.I. Ibrahim, 2011b. Characterization of titanium alloy feedstock for metal injection moulding using palm stearin binder system. Adv. Mater. Res., 264-265: 586-591.

DOI: 10.4028/www.scientific.net/AMR.264-265.586

Mohamad Nor, N.H., N. Muhamad, A.K.A. Mohd Ihsan and K.R. Jamaludin, 2013. Sintering parameter optimization of Ti-6Al-4V metal injection molding for highest strength using palm stearin binder. Procedia Eng., 68: 359-364.

DOI: 10.1016/j.proeng.2013.12.192

Murr, L.E., S.A. Quinones, S.M. Gaytan, M.I. Lopez and A. Rodela et al., 2009. Microstructure and mechanical behavior of $\mathrm{Ti}-6 \mathrm{Al}-4 \mathrm{~V}$ produced by rapid-layer manufacturing, for biomedical applications. J. Mechanical Behav. Biomed. Mater., 2: 20-32. DOI: 10.1016/j.jmbbm.2008.05.004
Obasi, G.C., O.M. Ferri, T. Ebel and R. Bormann, 2010. Influence of processing parameters on mechanical properties of $\mathrm{Ti}-6 \mathrm{Al}-4 \mathrm{~V}$ alloy fabricated by MIM. Mater. Sci. Eng. A, 527: 3929-3935. DOI: $10.1016 /$ j.msea.2010.02.070

Omar, M.A., I. Subuki, N. Abdullah and M.F. Ismail, 2011. The influence of palm stearin content on the rheological behaviour of 316L stainless steel MIM compact. J. Sci. Technol.

Razali, R., Z. Abdullah, I. Subuki, M.H. Ismail and N. Muhamad, 2014. Feedstock characterization of elemental nickel and titanium powders mixture for metal injection moulding process. Applied Mechan. Mater., 575: 78-82.

DOI: 10.4028/www.scientific.net/AMM.575.78

Scott Weil, K., E. Nyberg and K. Simmons, 2006. A new binder for powder injection molding titanium and other reactive metals. J. Mater. Process. Technol., 176: 205-209.

DOI: 10.1016/j.jmatprotec.2006.03.154

Sotomayor, M.E., B. Levenfeld and A. Várez, 2011. Powder injection moulding of premixed ferritic and austenitic stainless steel powders. Mater. Sci. Eng. A, 528: 3480-3488.

DOI: $10.1016 /$ j.msea.2011.01.038

Subuki, I., 2010. Injection moulding of 3161 stainless steel powder using palm stearin based binder system. PhD Thesis, University Technology MARA (UiTM), Shah Alam.

Torres, Y., J.J. Pavón and J.A. Rodríguez, 2012. Processing and characterization of porous titanium for implants by using $\mathrm{NaCl}$ as space holder. J. Mater. Process. Technol., 212: 1061-1069. DOI: 10.1016/j.jmatprotec.2011.12.015 